\title{
RANCANG BANGUN SISTEM INFORMASI RETRIBUSI PERSAMPAHAN PADA DINAS LINGKUNGAN HIDUP KOTA TANGERANG
}

\author{
Giandari Maulani ${ }^{1}$ \\ Tia Maryani ${ }^{2}$ \\ Yully Brigita ${ }^{3}$
Dosen Sistem Informasi STMIK Raharja ${ }^{1}$, Mahasiswa jurusan Sistem Informasi STMIK Raharja ${ }^{2}$, Mahasiswa jurusan Teknik Informatika STMIK Raharja ${ }^{3}$
Jl. Jenderal Sudirman No.40, Modernland, Tangerang
Email : giandari@raharja.info ${ }^{1)}$, tia@raharja.info ${ }^{2)}$,yully@raharja.info ${ }^{3)}$

\begin{abstract}
ABSTRAK
Sistem informasi memegang peranan yang sangat penting didalam instansi pemerintahan untuk mengolah dan menyajikan data dan informasi menjadi lebih mudah, akurat, cepat dan juga dapat menyimpan data pembayaran secara otomatis. UPT Retribusi Persampahan di Dinas Lingkungan Hidup Kota Tangerang seringkali menghadapi permasalahan pada pendataan pembayaran retribusi persampahan sampai dengan pembuatan laporannya, karena sistem yang berjalan saat ini masih belum terkomputerisasi dengan baik, hal ini mengakibatkan tidak efektif dan efisiennya pemasukan data retribusi persampahan. Penelitian ini bermaksud akan membuat rancang bangun sistem informasi retribusi persampahan sebagai solusi untuk permasalahan tersebut. Adapun Metodologi Penelitian yang dilakukan yakni Metode pengumpulan data berupa observasi, wawancara dan study pustaka, Metode analisa menggunakan analisis PIECES, Metode perancangan menggunakan aplikasi Visual Paradigm for UML 6.4 enterprise Edition, bahasa pemrograman menggunakan PHP dan $H T M L$, untuk tampilan interface aplikasi menggunakan CSS, untuk database menggunakan MariaDB, untuk server menggunakan Apache, untuk Frameworknya menggunakan Laravel dan tahapan untuk mendesain menggunakan aplikasi Notepad++. Hasil akhir penelitian ini menghasilkan Website Sistem Informasi Retribusi Persampahan untuk Dinas Lingkungan Hidup Kota Tangerang.
\end{abstract}

Kata kunci: Sistem Informasi, Retribusi Persampahan, Website.

\begin{abstract}
Information systems holds a very important role in governmental agencies, to manipulate and present data and information becomes easier, accurate, fast and can also save the data of the payment automatically. UPT of Garbage Retribution in the service of the environment often face problems of Tangerang on logging Garbage Retribution payments up to making his report, because the system is currently running are still not computerized well, this has resulted in ineffective and inefficiency data entry of Garbage Retribution. The research is intended would make the information systems architecture of Garbage Retribution as a solution to these problems. As for the methodology of the research done i.e. method of data collection in the form of observation, interview and study library, the analysis method using analysis Method of design PIECES, using applications, Visual Paradigm for UML 6.4 enterprise Edition, using the programming language PHP and HTML, to display application interfaces using CSS, for database using MariaDB, to server using Apache, its Framework for using Laravel and stages to design using the application Notepad ++. The end result of this research resulted in the Website of Garbage Retribution information systems for Department of Environment City of Tangerang.
\end{abstract}

Keywords : Information Systems, Garbage Retribution, Website. 


\section{PENDAHULUAN}

\section{Latar Belakang}

Kebutuhan akan informasi yang cepat saat ini menjadi hal yang sangat penting di berbagai instansi pemerintahan didalam mengolah dan menyajikan data pembayaran menjadi mudah, akurat dan cepat serta dapat menyimpan data pembayaran secara otomatis terutama di instansi pemerintahan, yang dalam hal ini difokuskan pada UPT Retribusi Persampahan Dinas Lingkungan Hidup Kota Tangerang. Retribusi persampahan merupakan salah satu dari retribusi jasa umum yang memberikan kontribusi terhadap pendapatan asli daerah dan memiliki dasar hukum yang dikeluarkan Pemerintah Pusat dan Pemerintah Daerah. Pengolahan data retribusi persampahan yang akurat, efektif dan tepat bertujuan untuk mempermudah pembuatan pendataan laporan pembayaran secara berkala. Sistem informasi pendataan pembayaran pada UPT Retribusi Persampahan sendiri saat ini masih belum terkomputerisasi dengan baik sehingga pada proses pencatatan pendataan laporan pembayaran sering terjadi kekeliruan data, untuk itu diperlukan suatu sistem informasi yang dapat mempermudah pengguna dalam membuat laporan secara akurat dan cepat.

\section{Metodologi Penelitian}

Dalam melaksanakan penelitian ini digunakan beberapa metodologi penelitian, yaitu sebagai berikut :

\subsection{Metode Pengumpulan Data}

\section{A. Observasi (Observation)}

Penelitian ini menggunakan metode dengan cara observasi ke lokasi objek penelitian yaitu observasi langsung ke UPT Retribusi Persampahan untuk memperoleh data-data yang diperlukan dalam penyusunan penelitian ini.

B. Wawancara (Interview)

Melakukan wawancara kepada Bendahara Pembantu Penerima dan Petugas Pendata untuk menanyakan langsung apa saja sistem pendataan pembayaran yang sedang berjalan untuk mengetahui kekurangan atau masalah yang ada pada saat penginputan data pembayaran, pengolahan data, penyajian informasi serta pembuatan laporan setoran mingguan dan laporan rincian bulanan yang dalam hal ini yaitu dengan Bpk.Marjaih,S.IP,MAP, Ibu Fitriah dan ibu Ayunica Sukma.

C. Studi Pustaka (Literatur Review)

Studi pustaka dilaksanakan dengan tujuan untuk mengumpulkan data-data yang diperoleh melalui buku, jurnal serta karya ilmiah lainnya, yang berkaitan dengan pembahasan penelitian yang digunakan untuk bahan referensi dalam penelitian yang dilaksanakan.

\subsection{Metode Analisa}

Metode analisa pada penelitian ini menggunakan metode analisa PIECES (Performance, Information, Economic, Control, Efficiency, Service). Analisa PIECES ini sangat penting sebelum mengembangkan sebuah sistem informasi karena dalam analisis ini biasanya mengidentifikasi masalah sampai dengan menyelesaikan masalah.

\subsection{Metode Perancangan}

Metode perancangan yang digunakan yaitu aplikasi Visual Paradigma for UML 6.4 enterprise Edition untuk menggambarkan class Diagram, Use Case Diagram, Activity Diagram dan Sequence Diagram. Sedangkan untuk bahasa pemrograman yang digunakan yaitu PHP dan HTML, untuk tampilan antar muka aplikasi menggunakan CSS, MariaDB digunakan sebagai database, untuk server menggunakan Apache, Frameworknya menggunakan Laravel Sedangkan tahapan untuk mendesain menggunakan aplikasi Notepad++.

\subsection{Metode Pengujian (Testing)}

Metode pengujian ini digunakan untuk menganalisis suatu sistem untuk mendeteksi perbedaan antara kondisi yang diinginkan dengan kondisi yang ada (errors/bugs/defects) dan mengevaluasi kondisi dan fitur dari entitas software yang diinginkan untuk mengetahui dari suatu sistem yang terjadi saat sistem diterapkan. 


\section{PERMASALAHAN}

Setelah dilakukan analisa, maka terdapat beberapa rumusan masalah, yakni : 1) Apakah sistem informasi pada UPT Retribusi Persampahan di Dinas Lingkungan Hidup Kota Tangerang sudah efektif dan efisien? 2) Apakah sistem yang berjalan saat ini pada UPT Retribusi Persampahan sudah dapat menghasilkan laporan pembayaran retribusi persampahan dengan cepat, tepat dan akurat? 3) Apakah dengan adanya sistem informasi monitoring dapat membantu Ketua UPT Retribusi Persampahan dan Bendahara Pembantu Penerima dalam mengontrol pembayaran retribusi persampahan? Pertanyaan-pertanyaan diatas muncul karena yang menjadi permasalahan selama ini yakni mengenai penanganan retribusi persampahannya masih ditangani secara manual dan terlihat belum dapat memudahkan pekerjaan serta sistem yang ada belum dapat dijadikan dasar pengambilan keputusan karena lambatnya penanganan retribusi persampahan.

\section{LANDASAN TEORI}

\section{Landasan Teori}

Menurut Dini Hamidini [2017] $]^{2}$ Sistem adalah kumpulan dari elemen-elemen berupa data, jaringan kerja dari prosedur-prosedur yang saling berhubungan, sumber daya manusia, teknologi baik hardware maupun software yang saling berinteraksi sebagai satu kesatuan untuk mencapai tujuan/sasaran tertentu yang sama.

Menurut Muhammad Muslihudin [2016] $]^{7}$ Informasi adalah "data yang diolah menjadi bentuk yang berguna untuk membuat keputusan".

Menurut Ayu Mayangsari $[2015]^{1}$ Pendataan adalah Keterangan yang benar dan bahan nyata yang dapat dijadikan sebagai dasar kajian (analisis atau kesimpulan).

Menurut J. Riwu kaho [2016] ${ }^{6}$ Retribusi adalah pungutan daerah sebagai pembayaran pemakaian atau karena jasa pekerjaan, usaha/milik daerah untuk kepentingan umum atau karena jasa yang diberikan oleh daerah baik langsung maupun tidak langsung.

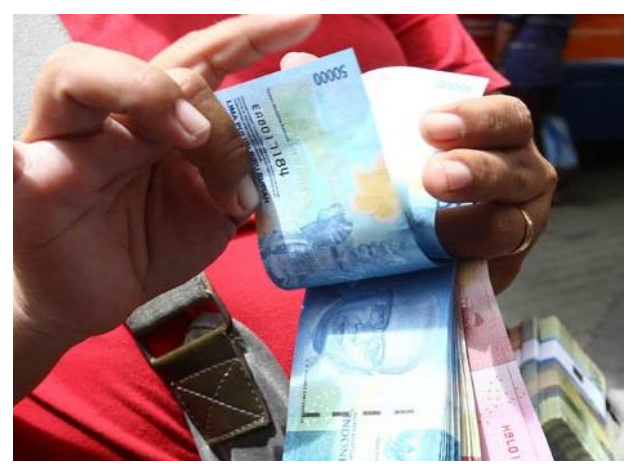

Gambar 1. Uang Retribusi Persampahan

\section{LITERATUR REVIEW}

Pengertian Literature review menurut Jesa Ariawan dan Sri Wahyuni [2015] $]^{5}$ adalah Mempelajari teori-teori dan mencari informasi yang berhubungan dengan permasalahan sesuai dengan judul penelitian. Dalam upaya menyempurnakan penelitian maka perlu dilakukan studi pustaka (Literature Review), diantaranya yaitu:

1. Penelitian yang dilakukan oleh Zamzami $[2017]^{10}$ dalam International Journal of Economics, Commerce and Management United Kingdom yang berjudul : "In-Depth Exploration Of Market Retribution In Jambi Province, Indonesia", Penelitian ini bertujuan untuk menganalisis terwujudnya penerimaan retribusi pasar di Kota Jambi, metode yang digunakan dalam penelitian ini adalah metode analisis deskriptif kuantitatif, untuk terwujudnya penerimaan retribusi pasar di Kota Jambi periode 2006 sampai 2015. 
2. Penelitian Putri Wulan Septiantari dan Sukadi $[2014]^{8}$ dalam Jurnal IJNS - Indonesian Journal on Networking and Security Vol.3 No.3 yang berjudul : "Sistem Informasi Pendataan Pembayaran Siswa Pada Lembaga Bimbingan Belajar Be Excellent Pacitan Berbasis Web". Penelitian ini membahas mengenai pelaporan pembayaran pendaftaran siswa, baik siswa baru maupun siswa yang melakukan daftar ulang. Penelitian ini mengembangkan fitur untuk para siswa agar dapat melakukan pembayaran secara Online, sehingga orang tua siswa bisa mengetahui informasi tentang pembayaran anaknya dengan lebih mudah.

3. Penelitian yang dilakukan oleh ilyas Abdullah [2014 $]^{4}$ Universitas Islam Indragiri (UNISI) dalam Jurnal Sistemasi yang berjudul : "Analisa dan Perancangan Sistem Informasi Pembayaran Pajak/Retribusi Daerah pada UPT. Dipenda Kecamatan Gaung Kabupaten Indragiri Hilir". Kesimpulan dalam penelitian ini yakni pembuatan laporan pengolahan data tiket pada UPT.Dipenda Kecamatan Gaung yang berhubungan dengan informasi pembayaran pajak dapat dilakukan dengan baik dan dapat meminimalkan kesalahan-kesalahan setelah menerapkan sistem terkomputerisasi pada sistem pembayaran pajaknya.

4. Penelitian yang dilakukan oleh Dario De Judicibus, Sandro Leopardi, Leonardo Modeo, dan Nicola Pergola $[2013]^{3}$ dalam Journal International United States Patent De Judicibus Et Al. yang berjudul : "Methode and System For Secured Transactions Over A Wireless Netrwork". Penelitian ini bertujuan untuk melakukan transaksi yang aman serta disediakan layanan pembayaran pada lokasi yang berbeda dan didukung oleh aplikasi server yang berlaku untuk transaksi pemesanan dan layanan pembayaran dengan menggunakan pesan Short Messaging Service (SMS) melalui $\mathrm{GSM} /$ jaringan nirkabel.

5. Penelitian yang dilakukan oleh Ulf Mattsson, Yigal Rozenberg dan Wilton [2013] ${ }^{9}$ dalam Journal International United States Patent Application Publication Mattsson et all yang berjudul : "Tokenization Of Payment Information In Mobile Environments". Penelitian ini bertujuan untuk tokenisasi data di mobile dan lingkungan pembayaran. pengguna dapat melakukan pembayaran dengan ponsel lalu register bisa mengirimkan nomor kartu kredit diterima dari handphone ke local server, server lokal ini dapat mengirimkan nomor kartu kredit ke bank, sistem pembayaran dapat dilakukan dengan mengirimkan informasi pembayaran token ke pembayaran jaringan yang terkait dengan transaksi, dimana seorang pengguna bisa mengirimkan informasi pembayaran ke pusat.

Perbedaan Literature review yang terdahulu dengan penelitian ini adalah :

1. Penelitian ini berbasis Website Online dengan menggunakan bahasa pemrograman PHP serta database yang digunakan yaitu MariaDB. MariaDB dipilih karena memiliki jumlah bug yang lebih sedikit, mempunyai kapasitas engine yang lebih banyak dan memiliki banyak fitur-fitur yang canggih serta sangat mudah bermigrasi ke MySQL.

2. Penelitian ini dibuat dengan tampilan design yang menarik dan user friendly yang mudah digunakan dalam pencarian data setoran dan pembayaran retribusi agar dengan cepat dapat dipahami oleh User. Tujuannya agar data-data yang ada disetiap bagiannya dapat dikumpulkan dalam satu sistem yang terintegrasi satu sama lain, agar dapat menghasilkan laporan retribusi persampahan secara otomatis, mudah, akurat dan cepat.

\section{PEMECAHAN MASALAH}

\section{Rancangan Sistem}

Rancangan sistem untuk rancang bangun sistem informasi retribusi persampahan pada Dinas Lingkungan hidup kota Tangerang digambarkan dengan diagram Unified Modeling Language/UML yang merupakan bahasa permodelan untuk software yang berorientasi objek, seperti dibawah ini : 


\section{A. Diagram Usecase}

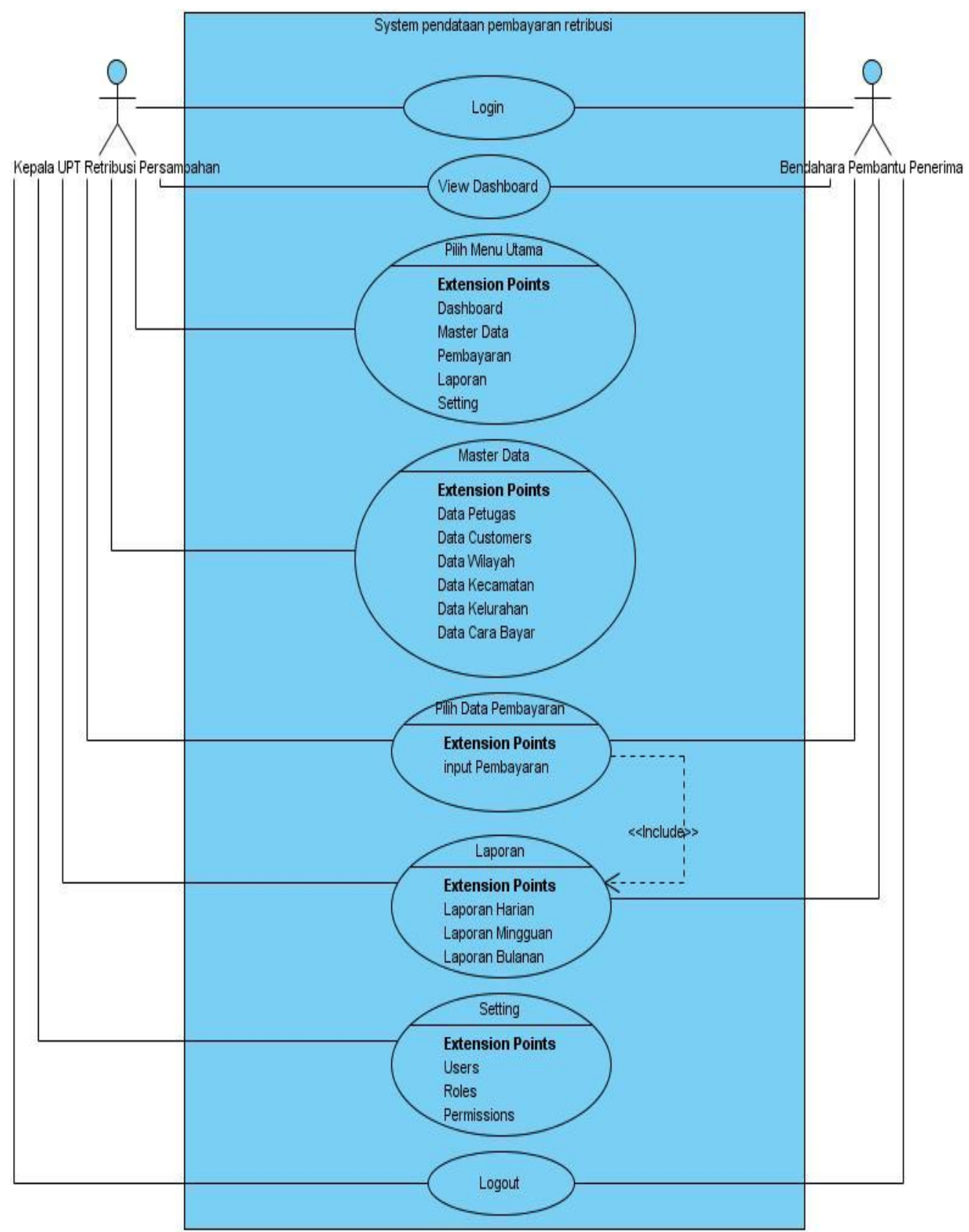

Gambar 2. Use case diagram sistem

Berdasarkan gambar 1. Use case diagram sistem, terdapat: 1 Sistem mencakup seluruh kegiatan dalam proses pendataan pembayaran retribusi, 2 actor yang melakukan kegiatan, diantaranya : Kepala UPT Retribusi Persampahan dan Bendahara Pembantu Penerima, didalam Usecase diagram tersebut terdapat : 1 include Login, 1 include View Dashboard, 5 Extend Use Case : Pilih Menu utama, Master Data, Pilih Data Pembayaran, Laporan, Setting dan 1 include Logout. 


\section{B. Diagram Sequence}

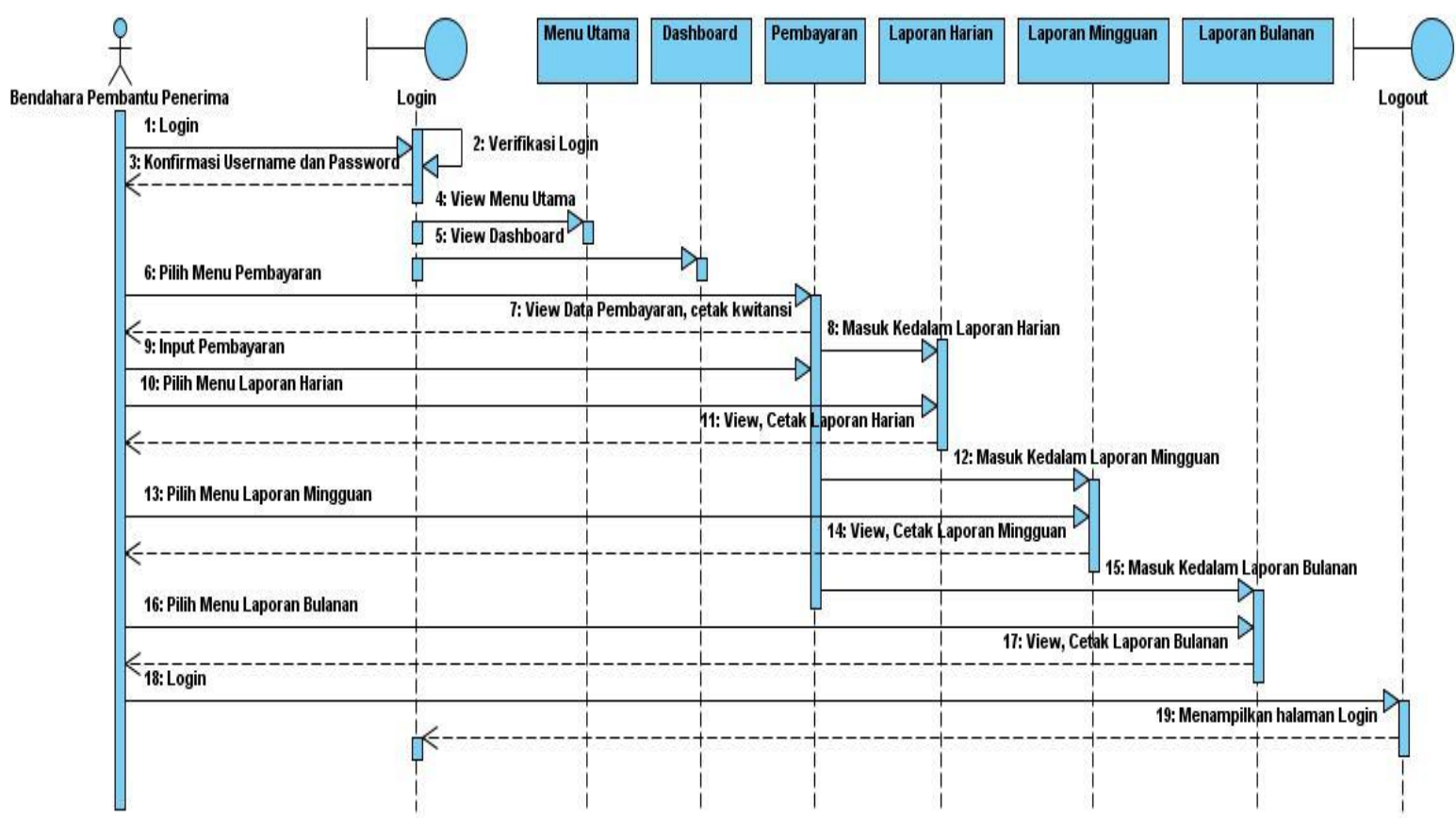

Gambar 3. Sequence diagram sistem

Pada gambar 3. Sequence diagram untuk Bendahara Pembantu Penerima terdapat: 1 actor yang melakukan kegiatan, yaitu Bendahara Pembantu Penerima, 6 lifeline yang saling berinteraksi, yaitu Menu Utama, Dashboard, Pembayaran, Laporan Harian, Laporan Mingguan dan Laporan Bulanan, 2 boundary lifeline, yaitu Login dan Logout, 19 Message yang memuat informasi-informasi tentang suatu kegiatan atau aktivitas yang terjadi yang dilakukan oleh actor.

\section{Uji Validitas}

Metode pengujian/Uji Validitas pada penelitian ini menggunakan Blackbox Testing. Blackbox Testing merupakan metode pengujian perangkat lunak yang memfokuskan kepada keperluan software, oleh karena itu metode Blackbox Testing ini dapat mengetahui dan memastikan apakah pemasukan data diterima dengan benar dan keluaran data yang dihasilkan sesuai dengan yang diharapkan. 
Tabel 1. Blackbox Testing pada Menu Login

\begin{tabular}{|c|c|c|c|c|c|}
\hline $\begin{array}{l}\mathbf{N} \\
\mathbf{o}\end{array}$ & $\begin{array}{l}\text { Skenario } \\
\text { Pengujian }\end{array}$ & Test Case & $\begin{array}{l}\text { Hasil yang } \\
\text { diharapkan }\end{array}$ & Hasil Pengujian & Ket. \\
\hline 1 & $\begin{array}{l}\text { Jika memasukan } \\
\text { data username atau } \\
\text { password dengan } \\
\text { Salah dan langsung } \\
\text { klik tombol login. }\end{array}$ & $\begin{array}{l}\text { UPT Retribusitersampahan } \\
\text { Kota Tangerang } \\
= \\
=-\end{array}$ & $\begin{array}{l}\text { Sistem akan } \\
\text { menolak akses } \\
\text { login dan } \\
\text { menampilkan } \\
\text { pesan "These } \\
\text { credentials do } \\
\text { not match our } \\
\text { records". }\end{array}$ & $\begin{array}{l}\text { UPT Retribusifi Persampahan } \\
\text { Kota Tangerang }\end{array}$ & Valid \\
\hline 2 & $\begin{array}{l}\text { Jika memasukan } \\
\text { data username atau } \\
\text { password dengan } \\
\text { Benar dan langsung } \\
\text { klik tombol login. }\end{array}$ & 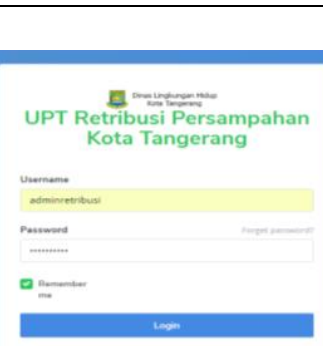 & $\begin{array}{l}\text { Sistem akan } \\
\text { menerima akses } \\
\text { dan secara } \\
\text { otomatis masuk } \\
\text { ke halaman } \\
\text { menu utama } \\
(\text { dashboard }) \text {. }\end{array}$ & $\sum^{5}$ & Valid \\
\hline
\end{tabular}

Tabel 2. Black Box Testing Input Data Petugas

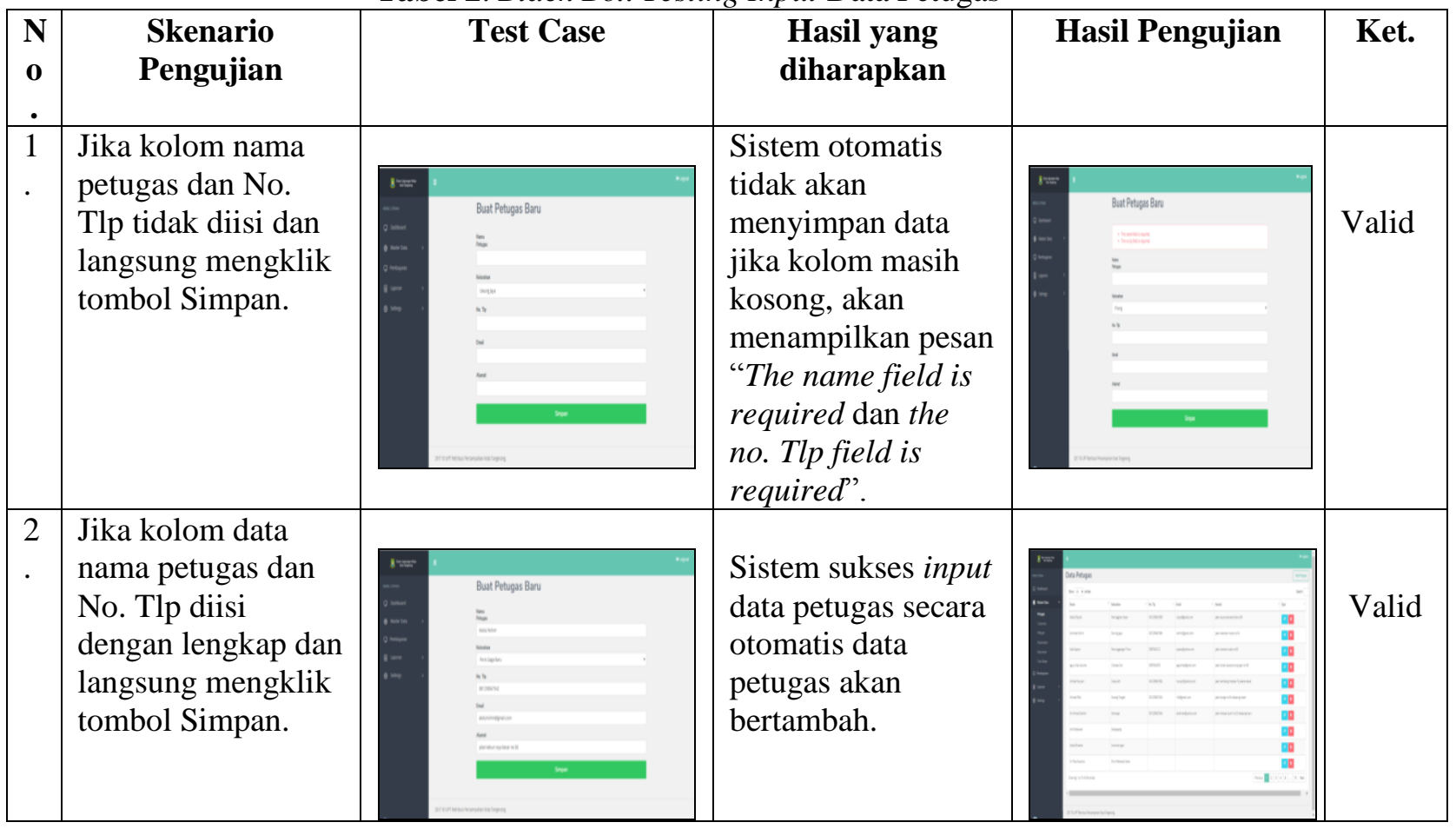


Tabel 3. Black Box Testing Input Data Customer

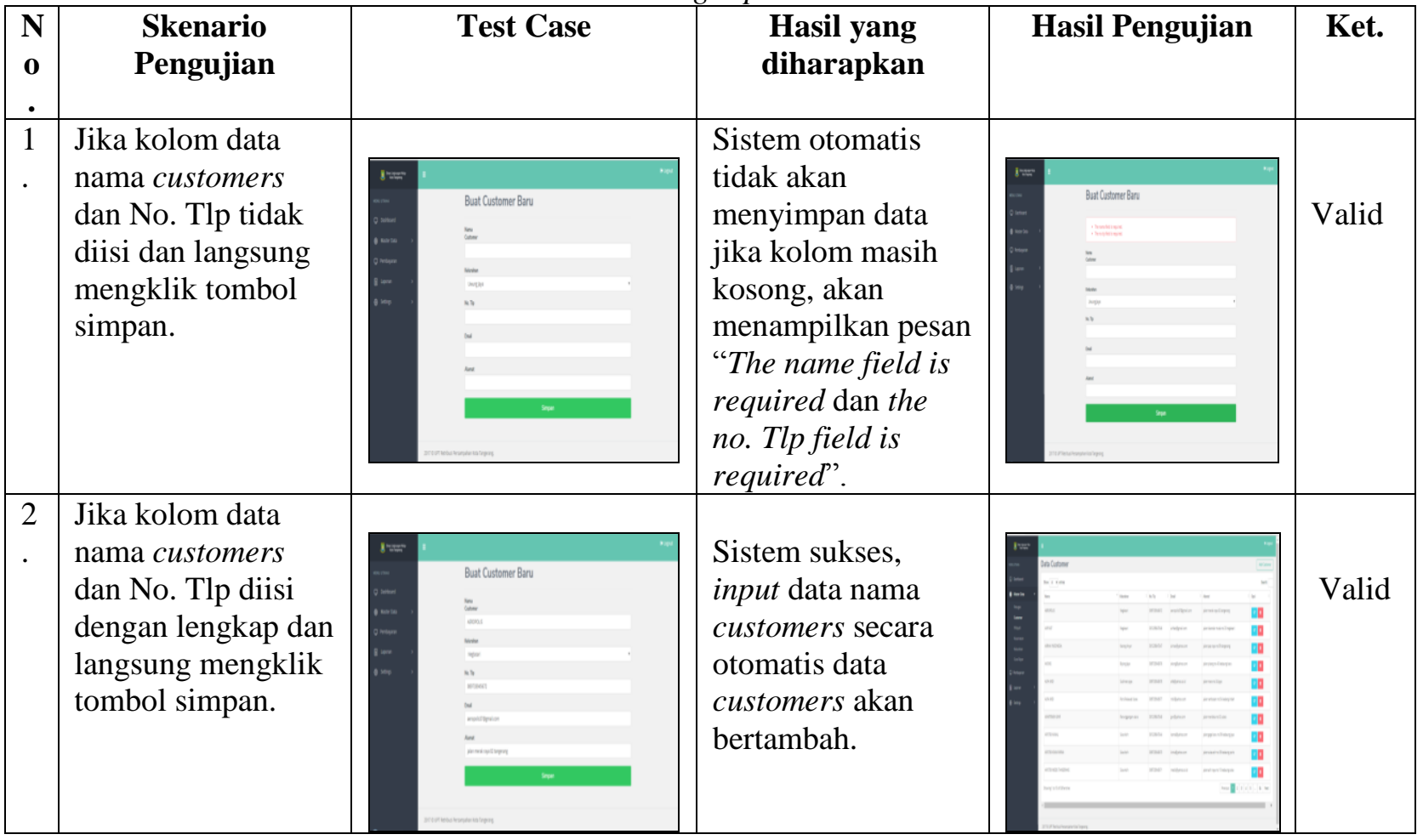

Tabel 4. Black Box Testing Data Wilayah

\begin{tabular}{|c|c|c|c|c|c|}
\hline $\begin{array}{l}\mathbf{N} \\
\mathbf{o}\end{array}$ & $\begin{array}{l}\text { Skenario } \\
\text { Pengujian }\end{array}$ & Test Case & $\begin{array}{c}\text { Hasil yang } \\
\text { diharapkan }\end{array}$ & Hasil Pengujian & Ket. \\
\hline 1 & $\begin{array}{l}\text { Jika kolom nama } \\
\text { wilayah tidak diisi } \\
\text { dan langsung } \\
\text { mengklik tombol } \\
\text { simpan. }\end{array}$ & $\begin{array}{l}\text { But Waph bin } \\
=\end{array}$ & $\begin{array}{l}\text { Sistem otomatis } \\
\text { tidak akan } \\
\text { menyimpan data } \\
\text { jika kolom masih } \\
\text { kosong, akan } \\
\text { menampilkan pesan } \\
\text { "The name field is } \\
\text { required" }\end{array}$ & $=$ & Valid \\
\hline 2 & $\begin{array}{l}\text { Jika kolom data } \\
\text { nama wilayah diisi } \\
\text { dengan lengkap dan } \\
\text { langsung mengklik } \\
\text { tombol simpan. }\end{array}$ & 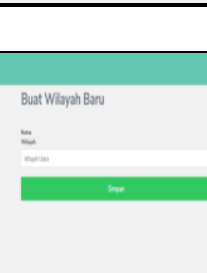 & $\begin{array}{l}\text { Sistem sukses input } \\
\text { data wilayah secara } \\
\text { otomatis data } \\
\text { wilayah akan } \\
\text { bertambah. }\end{array}$ & $=\left[\begin{array}{lll}\cdots \\
-\end{array}\right.$ & Valid \\
\hline
\end{tabular}


Tabel 5. Black Box Testing Cara Bayar

\begin{tabular}{|c|c|c|c|c|c|}
\hline $\begin{array}{l}\mathbf{N} \\
\mathbf{0}\end{array}$ & $\begin{array}{l}\text { Skenario } \\
\text { Pengujian }\end{array}$ & Test Case & $\begin{array}{c}\text { Hasil yang } \\
\text { diharapkan }\end{array}$ & Hasil Pengujian & Ket. \\
\hline 1 & $\begin{array}{l}\text { Jika kolom nama } \\
\text { cara bayar tidak } \\
\text { diisi dan langsung } \\
\text { mengklik tombol } \\
\text { simpan. }\end{array}$ & $\begin{array}{l}\text { Buat Carb Bayar Banu } \\
\vdots \\
\end{array}$ & $\begin{array}{l}\text { Sistem otomatis } \\
\text { tidak akan } \\
\text { menyimpan data } \\
\text { jika kolom masih } \\
\text { kosong, akan } \\
\text { menampilkan pesan } \\
\text { "The name field is } \\
\text { required". }\end{array}$ & $\begin{array}{l}\text { Butcan bopelion } \\
\vdots \\
\vdots\end{array}$ & Valid \\
\hline 2 & $\begin{array}{l}\text { Jika kolom data } \\
\text { nama cara bayar } \\
\text { diisi dengan } \\
\text { lengkap dan } \\
\text { langsung mengklik } \\
\text { tombol simpan. }\end{array}$ & $\begin{array}{l}\text { Bunctan Bure bin } \\
\vdots \\
\end{array}$ & $\begin{array}{l}\text { Sistem sukses input } \\
\text { data cara bayar } \\
\text { secara otomatis } \\
\text { data cara bayar } \\
\text { akan bertambah. }\end{array}$ & $\begin{array}{l}\text { 哭 } \\
\text { 吅 } \\
\text { 口口 }\end{array}$ & Valid \\
\hline
\end{tabular}

\section{IMPLEMENTASI}

Dibawah ini merupakan hasil implementasi interface tampilan setiap menu dari Sistem Informasi Retribusi Persampahan yang berbasis Website :

\section{Tampilan Menu Login}

Untuk tampilan menu login yang merupakan hal utama didalam mengimplementasikan program yang telah dibuat dengan username atau password yang dimasukkan harus benar. Tampilan login ini menjaga sistem supaya tidak bisa dimasuki oleh sembarangan orang, yang berhak untuk melakukan login hanya kepala UPT Retribusi dan Bendahara Pembantu Penerima.

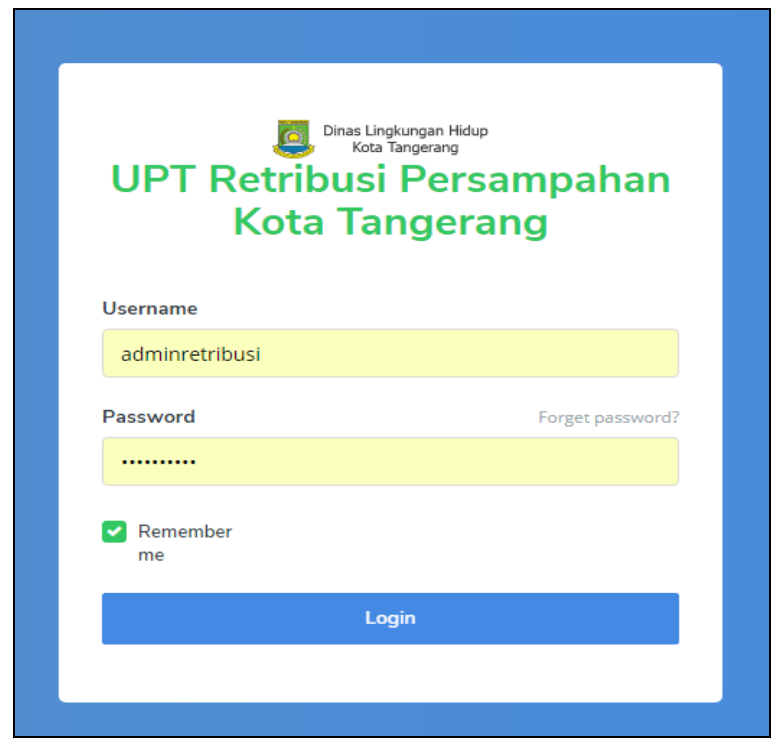

Gambar 4. Halaman Login

\section{Tampilan Menu Utama (Dashboard)}

Menu Utama (Dashboard) merupakan tampilan awal setelah melakukan login sistem yang berisi : Menu master data (petugas, customers, wilayah, kecamatan, kelurahan, metode pembayaran), Menu 
pembayaran dan Menu laporan (laporan harian, laporan mingguan, laporan bulanan) serta Menu setting (users, roles, permissions).

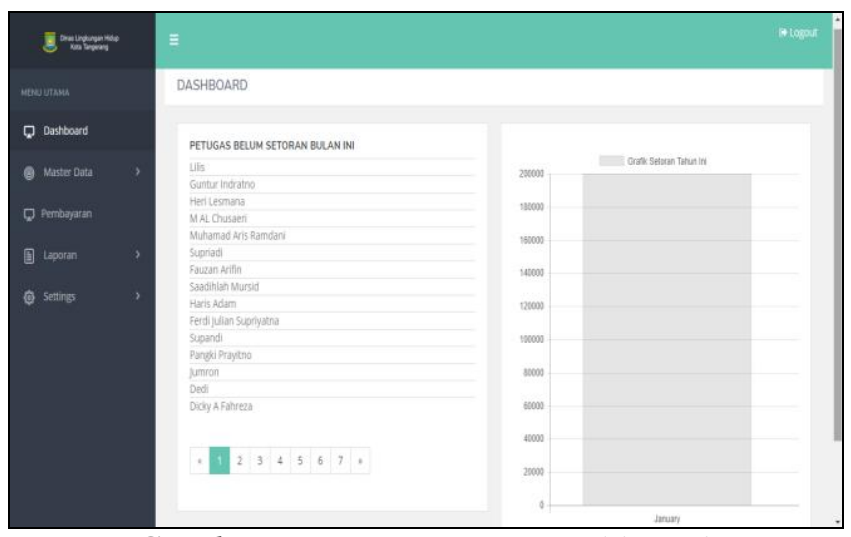

Gambar 5. Menu Utama (Dashboard)

\section{Tampilan menu Master Data Petugas}

Tampilan menu Master Data Petugas :

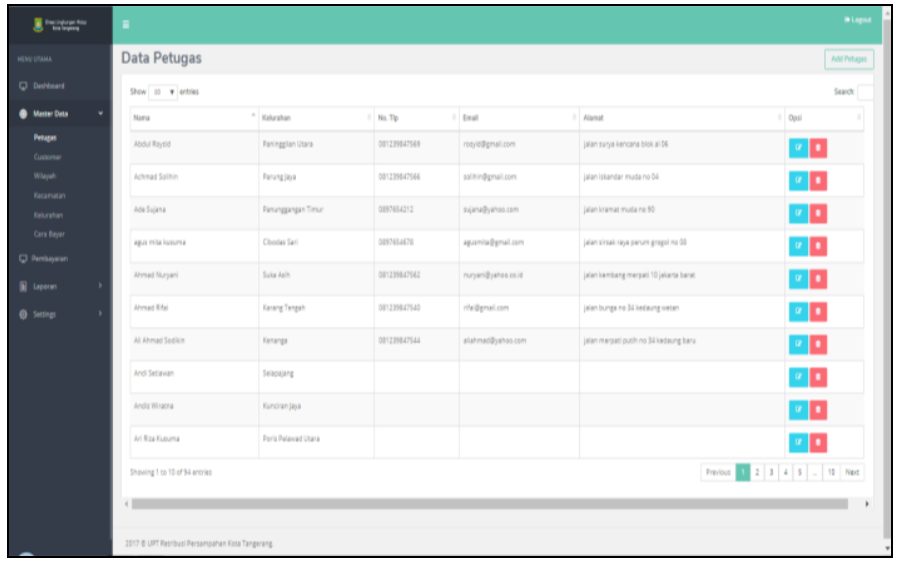

Gambar 6. Menu Master Data Petugas

Klik tombol Tambah, maka tampilan program input master data petugas seperti ini :

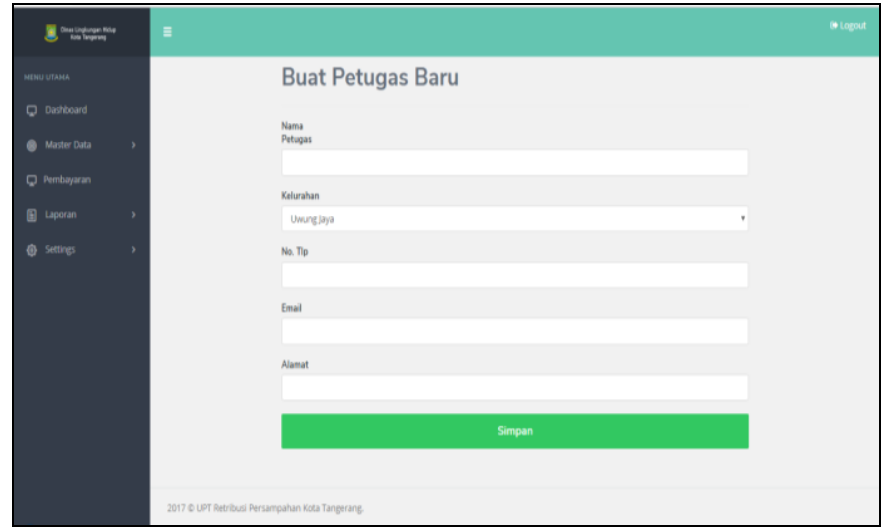

Gambar 7. Menu input master data petugas 


\section{Tampilan menu Master Data Customers}

Tampilan menu master data customers sebagai berikut :

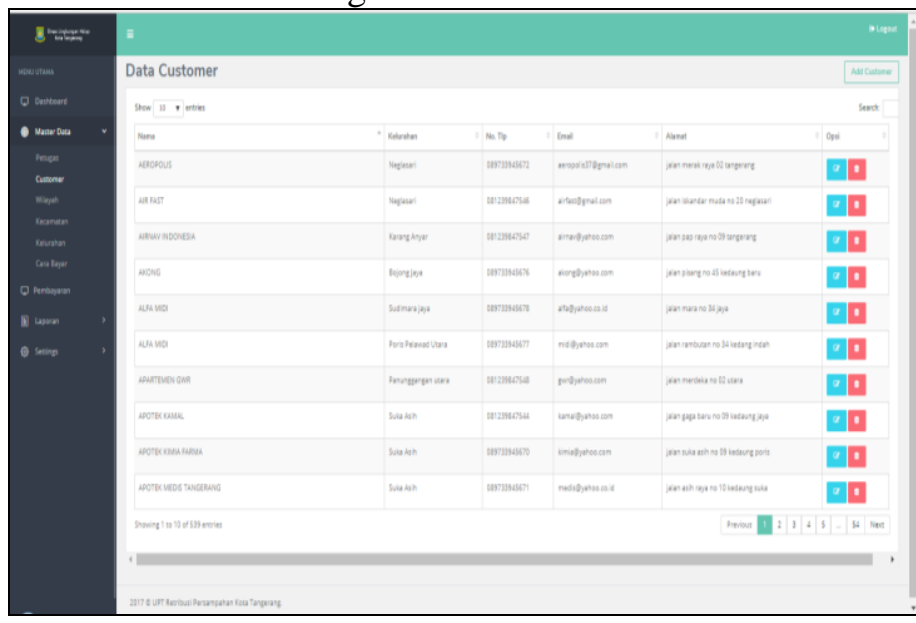

Gambar 8. Menu Master Data Customers

Klik tombol Tambah, maka tampilan program input master data customersnya seperti ini :

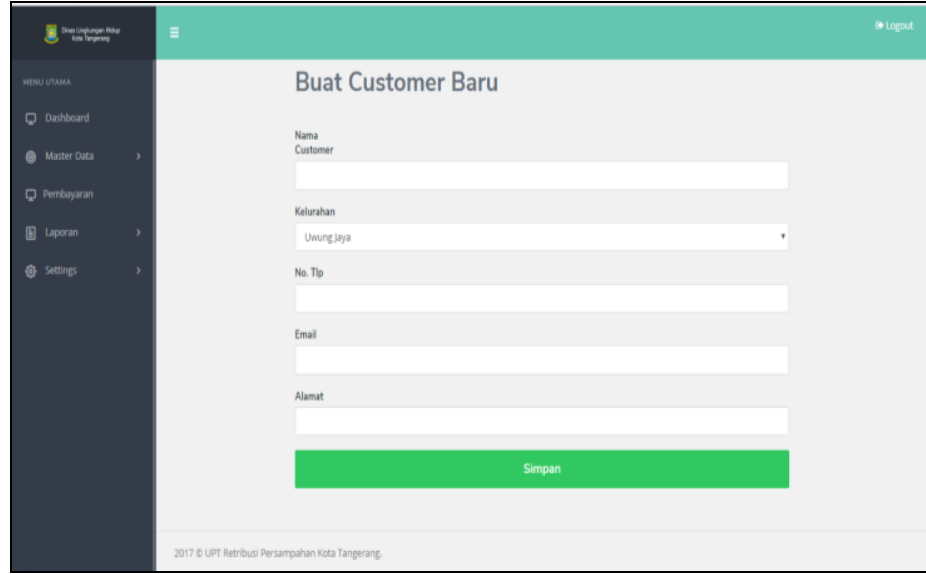

Gambar 9. Menu input master data customers

\section{Tampilan menu Master Data Wilayah}

Tampilan menu master data wilayah sebagai berikut :

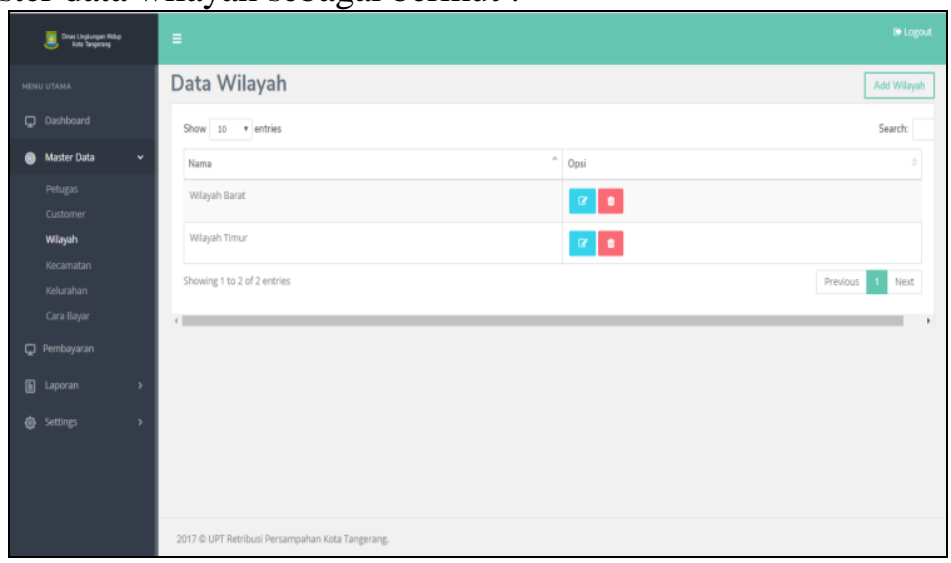

Gambar 10. Menu input master data wilayah

Klik tombol Tambah, maka tampilan program input master data wilayahnya seperti ini : 


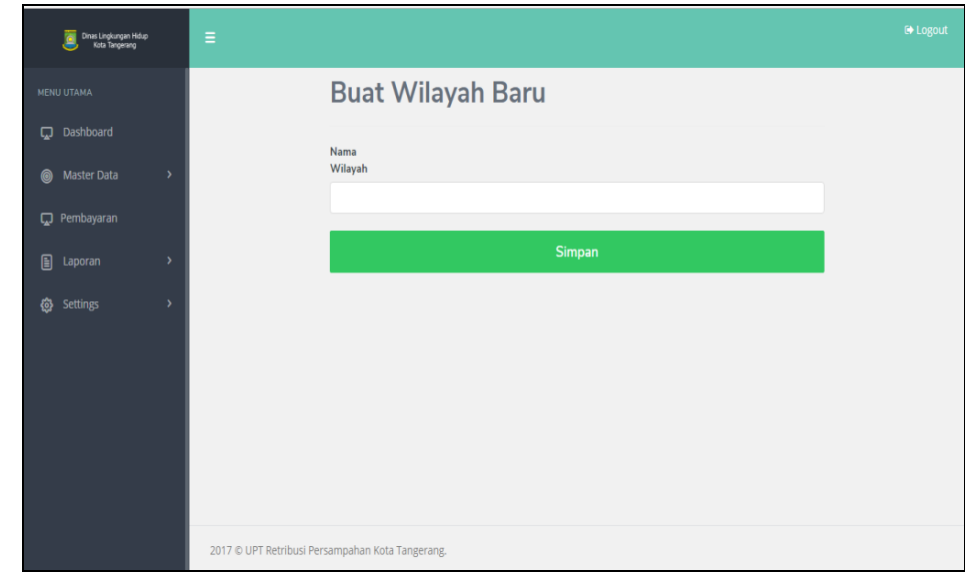

Gambar 11. Menu input master data wilayah

6. Tampilan menu Master Data Cara Bayar

Tampilan menu master data cara bayar sebagai berikut :

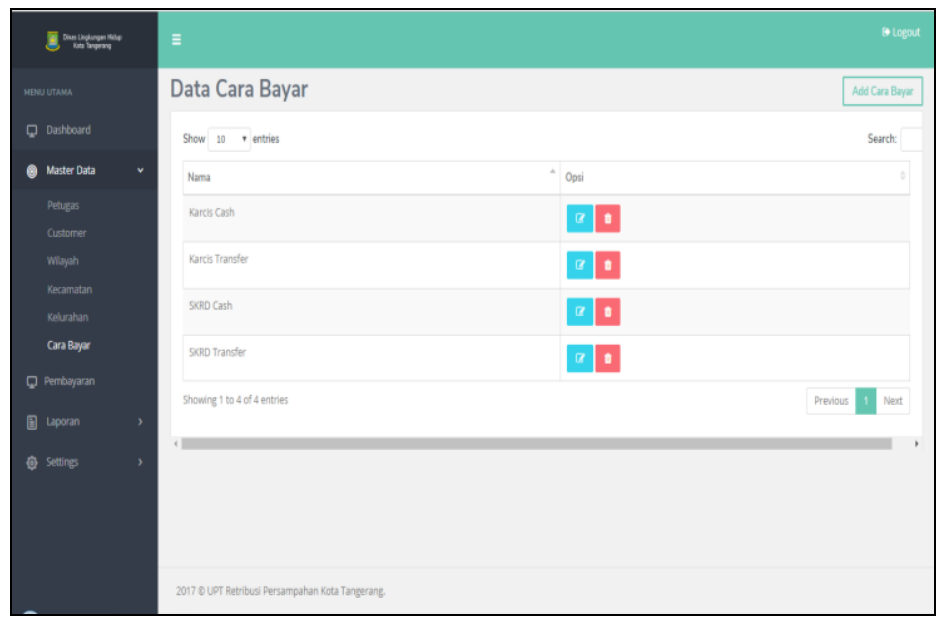

Gambar 12. Menu input master data cara bayar

Klik tombol Tambah, maka tampilan program input master data cara bayar, sebagai berikut :

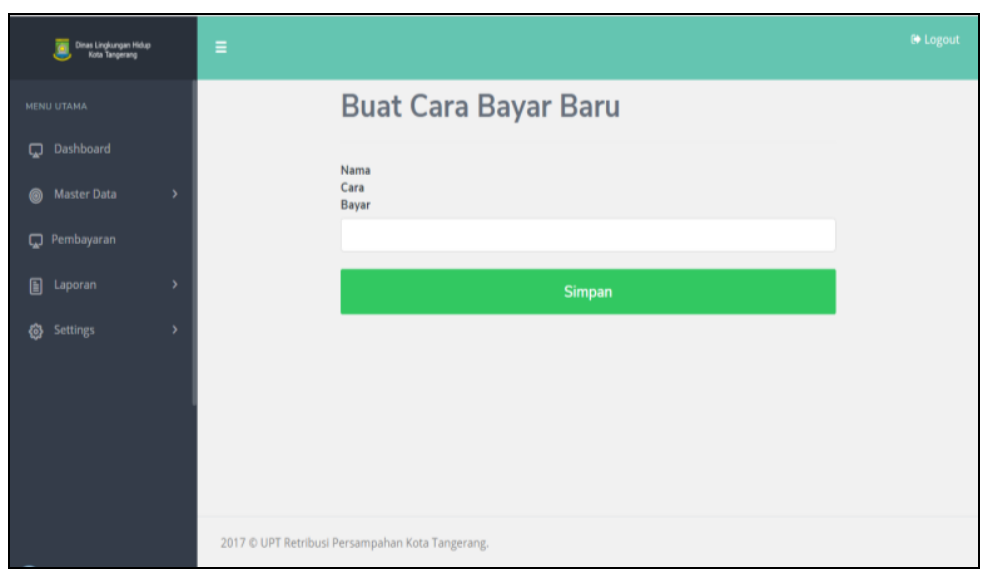

Gambar 13. Menu input master data cara bayar 
7. Tampilan menu Data Pembayaran

Tampilan menu data pembayarannya sebagai berikut :

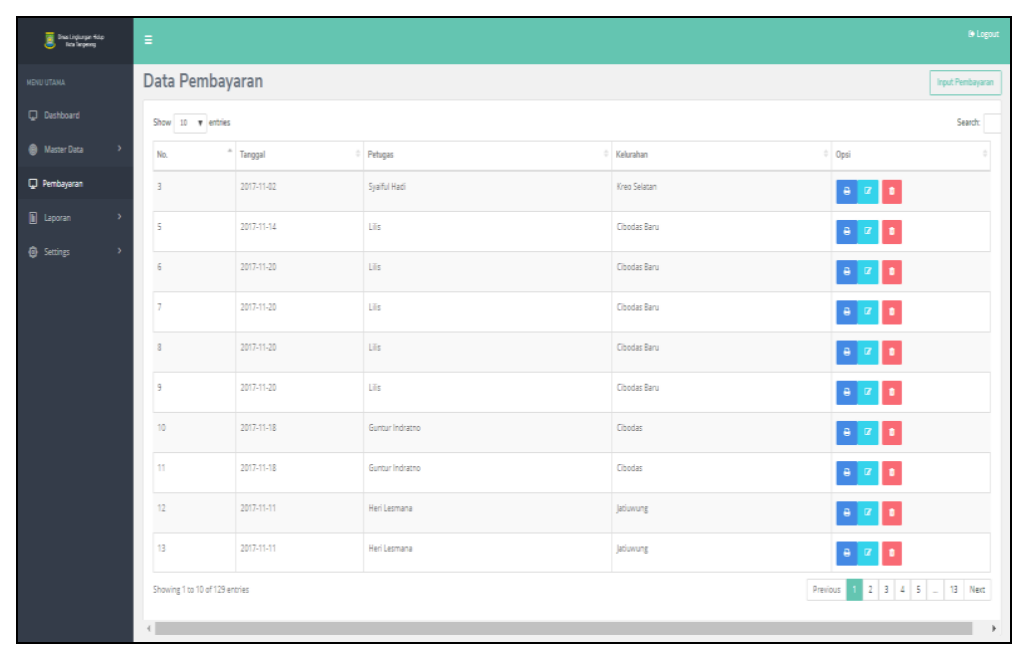

Gambar 14. Menu input data pembayaran

Klik tombol Tambah, maka tampilan menu input data pembayarannya seperti ini :

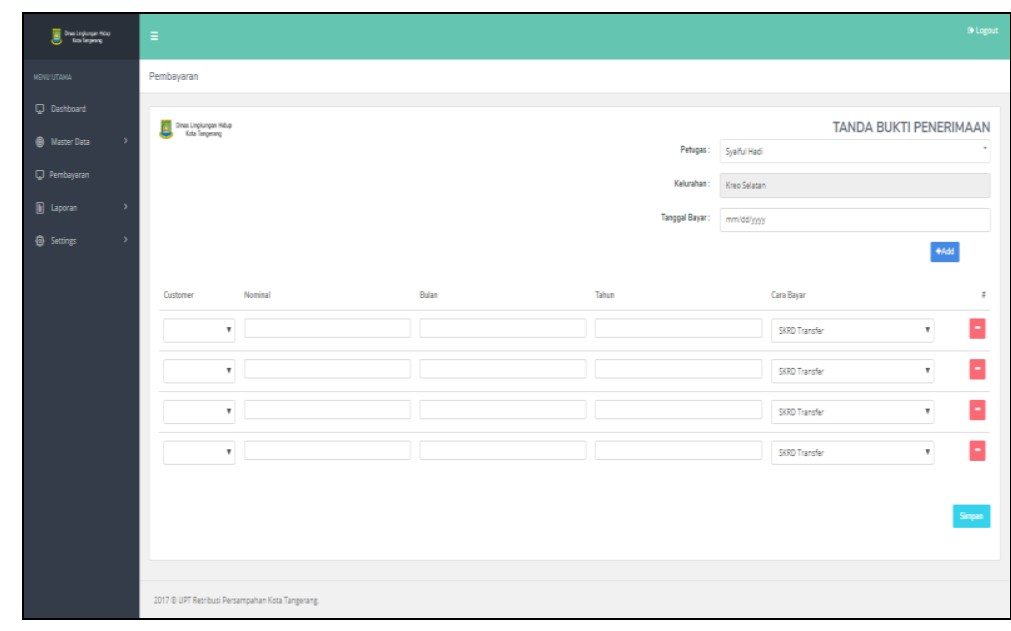

Gambar 15. Menu input data pembayaran 
8. Tampilan menu Laporan Bulanan

Tampilan menu laporan bulanan ditunjukkan pada gambar dibawah ini :

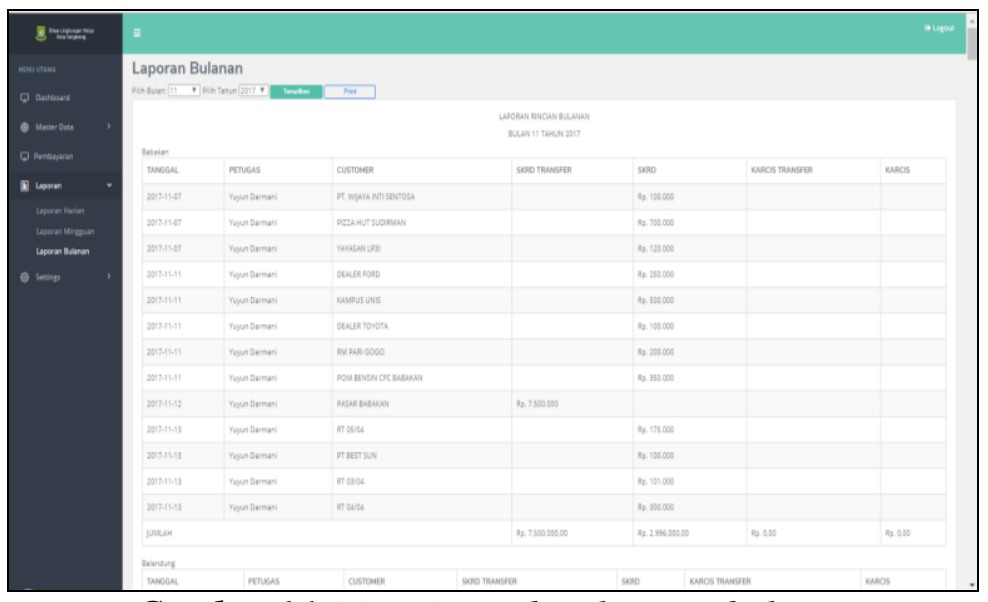

Gambar 16. Menu input data laporan bulanan

\section{KESIMPULAN}

Berdasarkan hasil penelitian yang telah dilakukan, maka diambil kesimpulan,yaitu: Sistem informasi pada UPT Retribusi Persampahan di Dinas Lingkungan Hidup Kota Tangerang saat itu belum efektif dan efisien karena proses penginputan data pembayarannya masih manual dengan cara: Bendahara Pembantu Penerima harus mencatat di daftar setoran retribusi, setelah itu Bendahara Pembantu Penerima merekap setoran mingguan dan merekap rincian bulanan. Selain itu, sistem yang berjalan saat ini pada UPT Retribusi Persampahan belum dapat menghasilkan laporan pembayaran retribusi persampahan dengan cepat, tepat dan akurat karena belum terkomputerisasi dengan baik, sehingga proses pencatatan laporan setoran mingguan dan laporan rincian bulanan sering terjadi kekeliruan. Solusi dari permasalahan di atas yakni dengan membuatkan sistem informasi yang terkomputerisasi untuk retribusi persampahan yang saling terintegrasi satu sama lain, sehingga data yang dihasilkan berjalan dengan cepat, tepat, akurat, efektif dan efisien. Adanya sistem informasi monitoring terbukti dapat membantu Ketua UPT Retribusi Persampahan dan Bendahara Pembantu Penerima dalam mengontrol pembayaran retribusi persampahan, karena tidak harus mengecek satu persatu dalam pencarian data yang sudah bayar maupun belum untuk melakukan setoran pembayaran retribusi persampahan dari 104 orang petugas pemungut retribusi se-kota Tangerang, selain itu dalam proses setoran pembayarannya dapat dipantau langsung oleh Bendahara Pembantu Penerima dan Ketua UPT Retribusi Persampahan dalam waktu yang cepat.

\section{SARAN}

Saran untuk pengembangan sistem informasi pembayaran retribusi persampahan agar menjadi lebih baik, yaitu : Disarankan agar UPT Retribusi Persampahan melakukan perawatan pada sistem yang telah dibuat ini agar selalu uptodate dan dapat menambahkan ruang lingkup pada pembayaran retribusi sehingga cakupan sistem menjadi lebih luas. Disarankan adanya pelatihan untuk Bendahara Pembantu Penerima untuk lebih memahami proses alur kerja pada sistem saat ini sehingga memaksimalkan sistem baru yang telah di rancang. Disarankan agar sistem yang buat ini dapat didukung oleh perangkat yang baik dari peralatan software maupun hardware agar mencapai hasil yang maksimal.

\section{DAFTAR PUSTAKA}

[1] A.Mayangsari, Asnawati dan L.Yulianti, "Aplikasi pendataan pasien rujuk balik peserta Badan Penyelenggara Jaminan Sosial (BPJS) Bengkulu”. Jurnal Media Infotama. Bengkulu,Vol.11, 
No.2,September 2015. Diakses pada 12 Oktober 2017 dari: http://jurnal.unived.ac.id/index.php/jmi/article/view/257/236. Oktober 2017.

[2] D.Hamidini. "Analisis dan Perancangan Sistem Informasi Pembahasan Secara Praktis dengan Contoh Kasus". Yogyakarta: Deepublish, 2017.

[3] D.D.Judicibus, Sandro Leopardi, Leonardo Modeo, dan Nicola Pergola. "Methode and System For Secured Transactions Over A Wireless Netrwork". Journal International United States Patent De Judicibus Et Al. US 8,352,360 B2. Jan. 8, 2013.Diakses pada 13 Oktober 2017 dari : http://www.freepatentsonline.com/y2004/0267618.html.Oktober 2017.

[4] I.Abdullah. "Analisa dan Perancangan Sistem Informasi Pembayaran Pajak/Retribusi Daerah pada UPT.Dipenda Kecamatan Gaung Kabupaten Indragiri Hilir”.Jurnal Sistemasi. Universitas Islam Indragiri (UNISI). Vol.3 No.3-Juli 2014. Diakses pada 13 Oktober 2017 dari: http://sistemasi.ftik.unisi.ac.id/index.php/stmsi/article/view/145/pdf. Oktober 2017.

[5] J.Ariawan dan S.Wahyuni. "Aplikasi Pengajuan Lembur Karyawan Berbasis Web”, Jurnal Sisfotek Global. ISSN : 2088 - 1762. Vol.5 No.1-Maret 2015.

[6] J. Riwu kaho "Pengertian Retribusi". Diakses pada 24 Januari 2018 dari : http://www.suduthukum.com/2016/05/pengertian-retribusi.html. Januari 2018.

[7] M. Muslihudin. "Analisis dan Perancangan Sistem Informasi Menggunakan Model Terstruktur dan UML”. Yogyakarta : Andi Offset. 2016.

[8] P.W.Septiantari dan Sukandi. "Sistem Informasi Pendataan Pembayaran Siswa Pada Lembaga Bimbingan Belajar Be Excellent Pacitan Berbasis Web". IJNS - Indonesian Journal on Networking and Security. Vol.3 No.3-Juli Diakses pada 12 Oktober 2014 dari:http://download.portalgaruda.org/article.php?article=268756\&val=7110\&title=Sistem\%20I nformasi\%20Pendataan\%20Pembayaran\%20Siswa\%20Pada\%20Lembaga\%20Bimbingan\%20 Belajar\%20\%20Be\%20Excellent\%20Pacitan\%20Berbasis\%20Web.Oktober 2014.

[9] U.Mattsson, Y.Rozenberg dan Wilton. "Tokenization Of Payment Information In Mobile Environments". Journal International United States Patent Application Publication Mattsson et all. US 2013/0212019 A1 Aug. 15, 2013.

[10] Zamzami. "In-Depth Exploration Of Market Retribution In Jambi Province, Indonesia". International Journal of Economics, Commerce and Management. Vol. V, Issue 6, June 2017. 